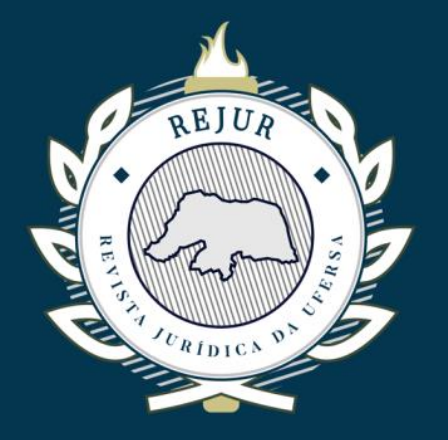

\title{
O DIREITO À RESERVA DA VIDA PRIVADA E DEVERES DE DIVULGAÇÃO DE DADOS DE ACIONISTAS
}

RIGHT TO PRIVACY RESERVE AND SHAREHOLDER DATA DISCLOSURE DUTIES

\author{
Jorge Manuel Coutinho de ABreu*
}

\section{RESUMO}

O direito à reserva da vida privada, embora direito de personalidade e (constitucionalmente) fundamental, é limitável em medida necessária e adequada à proteção de interesses relevantes. O texto ilustra brevemente algumas das limitações a esse direito no domínio do direito das sociedades comunitárioeuropeu.

Palavras-chave: Reserva da vida privada. Acionistas. Limitações.

\section{ABSTRACT}

The right to a private life reserve, while a (constitutionally) fundamental right of personality, is limited to the extent necessary and appropriate to the protection of relevant interests. The text briefly illustrates some of the limitations to this law in the field of Community-European company law ${ }^{1}$.

Keywords: Private life reserve. Shareholders. Limitations.

* Doutor e Mestre em Direito pela Faculdade de Direito pela Universidade de Coimbra, Portugal (FDUC). Professor Catedrático da FDUC. jabreu@fd.uc.pt

Recebido em 27-11-2018 | Aprovado em 27-11-2018²

\footnotetext{
${ }^{1}$ Elaborado pelos Editores.

${ }^{2}$ Artigo convidado. Texto

Texto da comunicação feita no IV Congresso Internacional Hispano-Luso-Brasileño Derechos Humanos/Direitos Humanos, realizado nos dias 4 e 5 de julho de 2018 na Facultad de Derecho da Universidad de Valladolid. Publicado anteriormente em: Direito das Sociedades em Revista, Coimbra, a. 10, v. 20, 2018, p. 13-19.
} 


\title{
SUMÁRIO
}

\author{
DIREITO À RESERVA DA VIDA PRIVADA (NÓTULA); 1 DIVULGAÇÃO DAS REMUNERAÇÕES DOS \\ ADMINISTRADORES; 2 PUBLICITAÇÃO DAS PARTES RELACIONADAS COM SOCIEDADE EM \\ NEGÓCIOS COM ELA REALIZADOS; 3 IDENTIFICAÇÃO DOS ACIONISTAS; 4 PUBLICITAÇÃO DOS \\ BENIFICIÁRIOS EFETIVOS; 5 SOCIEDADE “ANÓNIMA" E (NÃO) ANONÍMIA DAS AÇÕES; REFERÊNCIAS
}

\section{DIREITO À RESERVA DA VIDA PRIVADA (NÓTULA)}

Este direito, consagrado nas diversas constituições nacionais e em instrumentos internacionais (Declaração Universal dos Direitos do Homem, art. 12으, Pacto Internacional de Direitos Civis e Políticos, art. 17으, 1, Convenção Europeia dos Direitos do Homem, art. 8ㅇ), desdobra-se no poder de as pessoas interditarem o acesso a informações sobre as suas vidas privadas e no poder de impedirem a divulgação dessas informações por quem a elas tenha acedido, direta ou indiretamente e lícita ou ilicitamente.

A vida privada de uma pessoa compreende o modo de estar consigo mesmo (o ser e o atuar em solidão), os comportamentos de relação com os outros no recato do lar familiar e de outros lugares ou ambientes de privacidade, os atos de comunicação à distância (correspondência postal, telefónica, telemática) com esses outros (do círculo das relações de família, de afetos e outros de cariz pessoal). Em suma, é da vida privada o que está, ou deve estar, fora do alcance do olhar e dos ouvidos do público (menos ou mais extenso).

Como outros direitos de personalidade, o direito à reserva da vida privada protege $o$ "segredo do ser". É pelo menos duvidoso que proteja também "segredos do ter" tais como o segredo de recursos financeiros ou o segredo de aplicações do dinheiro. Seja como for, deve entender-se (e tem-se entendido) que estes "segredos do ter" são limitáveis na medida necessária e adequada à proteção de outros interesses relevantes, maxime interesses públicogerais (v.g., combate à corrupção, à fraude fiscal, ao branqueamento de capitais e ao financiamento de terrorismo).

Limitações ao sigilo do ter são bem aceitáveis em relação às sociedades mercantis. Por razões de transparência interna - as sociedades não são organizações monolíticas, os elementos constituintes do substrato pessoal e orgânico têm interesses diversos e às vezes conflituais. Mas também por razões de transparência externa - as sociedades vivem com e para as relações com terceiros, não são organizações fechadas de pessoas, e têm muitas vezes uma projeção socioeconómica e política que não pode ser ignorada pela instância políticojurídica.

Vamos então à ilustração breve destas ideias, apresentando alguns exemplos (principalmente) de direito comunitário-europeu. 


\section{DIVULGAÇÃO DAS REMUNERAÇÕES DOS ADMINISTRADORES ${ }^{3}$}

No princípio do século eram poucas as legislações nacionais que impunham a divulgação (individualizada) das remunerações de cada administrador. Embora muitos "códigos" de corporate governance a recomendassem. Apesar de alguns entenderem que o direito de personalidade dos administradores (mais precisamente, o direito à reserva da vida privada ou direito à autodeterminação informativa) inviabiliza, não havendo consentimento destes, a publicitação das remunerações. ${ }^{4}$

A tendência, hoje, é claramente a favor da publicitação. Marco importante é o art. 9oB da Diretiva 2007/36/CE (a chamada "diretiva dos direitos dos acionistas" - DDA), introduzido pela Diretiva (UE) 2017/828, de 17 de maio de 2017.

Esse artigo é todo dedicado à elaboração, votação e publicação de um relatório anual das sociedades cotadas sobre as remunerações atribuídas ou devidas a cada administrador no exercício social anterior. Depois de votado ou discutido em assembleia geral, o relatório deve ser disponibilizado ao público no sítio web da sociedade durante pelo menos 10 anos (10 parágrafo do $\mathrm{n}$ 5 do art. 9-B).

Como se diz no considerando (33) da Diretiva de 2017, esta divulgação promove mais transparência da sociedade, maior responsabilização dos administradores, melhor supervisão pelos acionistas, e facilita avaliações por parte de potenciais investidores e de outros interessados.

Compreensivelmente, o relatório não pode incluir dados pessoais dos administradores não necessários para os fins visados - v.g., dados sobre a origem racial ou étnica, as opiniões políticas ou filosóficas, a situação familiar (no 2 do art. 9--B).

\section{PUBLICITAÇÃO DAS PARTES RELACIONADAS COM SOCIEDADE EM NEGÓCIOS COM ELA REALIZADOS}

Nos negócios celebrados entre uma sociedade e parte (com ela) relacionada é muito frequente a existência de conflito de interesses: divergência de princípio entre o interesse da parte relacionada e o interesse da sociedade, convindo portanto àquela um negócio em certos termos e a esta negócio em termos diferentes.

Também nesta matéria, por demasiado tempo descurada, a citada Diretiva de 2017 trouxe contributos interessantes introduzindo o (longo) art. 9o-C na DDA. ${ }^{5}$

\footnotetext{
${ }^{3}$ Embora os administradores não tenham de ser acionistas - e são estes que aparecem no título deste trabalho -, são-no muitas vezes e, de todo o modo, parece oportuno referi-los aqui.

${ }^{4}$ V. referências em ABREU, J. M. COUTINHO DE., Governação das sociedades comerciais, 2a ed., Almedina, Coimbra, 2010, p. 91. Os Princípios de governo das sociedades do G20 e da OCDE, Editions OCDE, Paris, 2016, também recomendam a divulgação individualizada das remunerações ( $n$ 으., 4).

${ }^{5}$ Para uma análise do preceito, v. ABREU, J. M. COUTINHO DE., Remunerações dos administradores e transações com partes relacionadas na Diretiva dos Direitos dos Acionistas II, In: Direito das sociedades em revista, v. 19, Coimbra, 2018, p. 18-26.
} 
De acordo com a al. h) do art. 20 da Diretiva de 2007 (aditada pela Diretiva de 2017), que remete para a International Accounting Standard (IAS) no 24, é parte relacionada de uma sociedade (a) uma pessoa (humana) ou um membro próximo da família dessa pessoa que tem o controlo ou controlo conjunto sobre a sociedade ou influência significativa sobre ela , ou é membro do pessoal dirigente da sociedade ou de uma empresa controladora dela; (b) e uma entidade (coletiva) se, entre outras hipóteses, for membro, juntamente com a sociedade, de um mesmo grupo empresarial, ou for controlada por uma pessoa referida em (a). E, apesar de a Diretiva não definir "transações" (com parte relacionada), valerá também a noção oferecida pela IAS 24: transferência de recursos, serviços ou obrigações, independentemente de haver ou não um débito de preço - v.g., compras e vendas de bens, prestação e recebimento de serviços, locações, acordos financeiros, prestação de garantias.

Para aqui interessa especialmente chamar a atenção para o disposto no no 2 do art. 9o-C: "Os Estados-Membros devem assegurar que as sociedades anunciem publicamente as transações relevantes com partes relacionadas o mais tardar no momento em que forem realizadas. $O$ anúncio deve conter, no mínimo, informações sobre a natureza da relação com as partes relacionadas, o nome da parte relacionada, a data e o valor da transação e outras informações necessárias para avaliar se a transação é justa e razoável do ponto de vista da sociedade e dos acionistas que não são partes relacionadas, incluindo os acionistas minoritários".

O preceito não esclarece onde é feito o anúncio público. O considerando (44) da Diretiva diz que ele pode ser feito "num sítio web da sociedade ou por outros meios facilmente disponíveis".

\section{IDENTIFICAÇÃO DOS ACIONISTAS}

O direito de as sociedades cotadas conhecerem os seus acionistas detentores de participações qualificadas com direito de voto vem sendo atribuído pelas "diretivas da transparência" comunitário-europeias ${ }^{6}$.

Também nesta matéria algo avançou com a citada Diretiva 2017/828, que aditou à DDA o art. 3--A, precisamente epigrafado "Identificação dos acionistas".

Diz o no 1 deste artigo: "Os Estados-Membros devem assegurar que as sociedades tenham o direito de identificar os seus acionistas. Os Estados-Membros podem prever que as sociedades com sede social no seu território só sejam autorizadas a solicitar a identificação dos acionistas detentores de mais do que uma certa percentagem das ações ou dos direitos de voto. Essa percentagem não pode ser superior a 0,5\%." Este limiar (facultado, não imposto) de $0,5 \%$, apesar de em alguns casos poder ser demasiado alto e de não fazer sentido para as ações nominativas ${ }^{7}$, é ainda assim bem inferior aos limiares que têm sido estabelecidos nas "diretivas da transparência"8.

\footnotetext{
${ }^{6}$ Desde a Diretiva 88/627/CEE, de 12 de dezembro de 1988. V. agora a Diretiva 2004/109/CE, de 15 de dezembro de 2004, várias vezes alterada.

${ }^{7}$ Aliás, o art. 3ํ-A parece visar tão só as ações ao portador.

${ }^{8}$ A partir de 5\%, atualmente (art. 90, 1, da Diretiva 2004/109/CE).
} 
A pedido da sociedade, os intermediários (entidades que prestam serviços de guarda ou de administração de ações ou serviços de manutenção de contas de valores mobiliários em nome dos acionistas ou de outras pessoas: al. d) do art. 20 da DDA, acrescentada pela Diretiva de 2017) devem fornecer as informações relativas à identidade dos acionistas ( $n$ os 2 e 3 do art. 3--A), sem que isto possa ser considerado violação de "qualquer restrição da divulgação de informações imposta por contrato ou por qualquer disposição legislativa, regulamentar ou administrativa" (no 6).

As "informações relativas à identidade do acionista" incluem, segundo a al. j) do art. 20 da DDA (aditada também em 2017), o nome e os elementos de contacto do acionista e, no caso de ser pessoa coletiva, ainda o número de registo ou o seu identificador único; o número de ações detidas; e, quando solicitado pela sociedade, as categorias ou classes das ações detidas e/ou a data desde a qual as ações são detidas.

Os "dados pessoais" dos acionistas (pessoas singulares) devem ser tratados de modo a permitir que a sociedade identifique os seus acionistas a fim de com eles comunicar diretamente e assim facilitar o exercício dos direitos de socialidade e o envolvimento deles na vida da sociedade ( $n$ ㅇ 4, 1으 parágrafo, do art. 3--A). Porém, os Estados-membros "podem prever, por lei, o tratamento dos dados pessoais para outros fins (3ำ parágrafo desse $n 04$ ) v.g., para fins fiscais ou de supervisão a cargo de entidades públicas.

Terá sido esse acautelar do direito à reserva da vida privada e do tratamento dos dados pessoais que induziu o legislador da Diretiva de 2017 a atribuir o direito de conhecer a identificação dos acionistas apenas à sociedade, não à generalidade dos sócios. Cautela talvez exagerada, pois, além do mais ( $v$. supra, $\mathrm{n}$ o 1), nas sociedades só com ações nominativas o direito de informação dos sócios faculta o acesso àqueles dados pessoais.

\section{PUBLICITAÇÃO DOS BENIFICIÁRIOS EFETIVOS}

Contudo, às vezes é grande a opacidade das ações - nominativas ou (em maior grau) ao portador. Principalmente quando o titular nominal ou formal das ações não coincide com o titular económico ou material, isto é, aquele em cuja esfera jurídica se repercutem os resultados financeiros das ações (dividendos e quotas de liquidação e, em geral, os riscos e vantagens patrimoniais ligados às mesmas). Assim sucede com os nominees, trustees, Treuhänder e outros fiduciários, em suma todos quantos aparecem como titulares em nome próprio mas por conta de outrem ${ }^{9}$ - outrem que preserva o anonimato. E essa opacidade é em alguns casos impeditiva da proteção de certos interesses públicos.

\footnotetext{
${ }^{9}$ Sobre estas figuras (ou algumas delas), v. indicações em COURET, ALAIN., ADR, EDR, nominees, trustees, partnerships, global custodians, etc.", Rev. Sociétés, 1999, p. 554, s., MERKT, HANNO, "Die Geschichte der Namensaktie" em R. VON ROSEN / W. G.SEIFERT (Hrsg.), Die Namensaktie, Deutsches Aktieninstitut, 2000, p. 9092, HAMILTON, Robert W., The law of corporations, West Group, St. Paul-Minnesota, 2000, p. 258-259., S., MARTINS, AleXANDRe SOVERAL., Cláusulas do contrato de sociedade que limitam a transmissibilidade das acções, Almedina, Coimbra, n. 75, 2006, p. 224., GOWER \& DAVIES. Principles of modern company law, Sweet \& Maxwell, London, 2012, p. 455. FIGUEIREDO, ANDRÉ. Titularidade indireta de ações e exercício de direitos de voto, In: Revista de Direito das Sociedades, n. 3, a. 4, 2012, p. 512., s., MOHAMED, JEAN., Aktien und Aktienrepräsentanz im Zuge des Transparenzregisters (?),Vol. 38, n. 45, 2017, págs. 2133-2142., ANTUNES, José Engrácia (2018), "A
} 
Ora, a Diretiva (UE)2015/849, de 20 de maio de 2015, "relativa à prevenção da utilização do sistema financeiro para efeitos de branqueamento de capitais ou de financiamento do terrorismo", promove em boa medida maior transparência.

Para o que aqui interessa, e muito resumidamente, as sociedades (em geral) ficam obrigadas a obter e conservar informações sobre a identidade dos seus "beneficiários efetivos" (art. 30, 1), quer dizer, da "pessoa ou pessoas singulares que, em última instância detêm (...) o controlo da sociedade" - controlo direto ou indireto (art. 3ㅇ, 6) ${ }^{10}$. Essas informações são conservadas em um registo central (art. 30이). Acessível, sem restrições, às autoridades públicas competentes e, com algumas restrições, às "entidades obrigadas" (identificadas no art. 2ㅇ) e a "todos os membros do público" (art. 30ํ, 5 e 9) ) $^{11}$ - incluindo, portanto, os sócios da sociedade respetiva.

\section{SOCIEDADE “ANÓNIMA" E (NÃO) ANONÍMIA DAS AÇÕES}

Resulta do dito atrás que se vem assistindo à debilitação do anonimato nas sociedades anónimas. Mas não são as ações ao portador - anónimas - conaturais ou da essência de tais sociedades? Poderia pensar-se (e é pensamento frequente) que sim. Pois, de um lado, tais ações não mostram o nome dos titulares nos papeis em que são representadas e/ou ${ }^{12}$ não permitem, em geral, que a sociedade emitente conheça a todo o tempo a identidade dos titulares; de outro lado, esta anonímia (o sem nome, ou o nome geralmente não revelável) cola perfeitamente com a designação daquelas sociedades: "anónimas". Mas não é assim.

"Sociedade anónima" para designar o tipo societário atualmente assim chamado é locução que vem do Code de Commerce francês de 1807. Mas não foi adotada em todos os países, longe disso. Optaram alguns pela expressão "sociedade por ações" (Aktiengesellschaft, società per azioni, etc.), outros preferiram designações centradas em "corporação" (corporation) ou "companhia" (company), etc. Aliás, as sociedades avoengas das sociedades anónimas hodiernas eram (desde os primórdios do séc. XVII) designadas "companhias".

Sociedade "anónima" por quê? As sociedades deste tipo sempre tiveram nome... Para mais, antes do Code de 1807, "société anonyme" designava a figura hoje conhecida entre nós como "associação em participação" (Portugal), "sociedade em conta de participação" (Brasil), "cuenta en participación" (Espanha); e o Código Comercial português de 1833, no § 571 dizia da "associação em conta de participação" que "[e]sta sociedade também se denomina momentânea e anonyma". Designação que, afora a controversa qualificação da figura como sociedade, parece mais apropriada para ela do que para as modernas sociedades anónimas. Com efeito, a sociedade em participação não tinha nome ou firma, não aparecia ao público

titularidade por conta de participações sociais - breve apontamento". Direito das Sociedades em Revista, a. 10, v. 19. Lisboa: Almedina, pp. 51-70.

${ }^{10}$ No entanto, este preceito exceciona (muito discutivelmente, tendo em vista até a referida Diretiva 2017/828) as sociedades cotadas "num mercado regulamentado sujeita[s] a requisitos de divulgação de informações consentâneas com o direito da União ou sujeita[s] a normas internacionais equivalentes que garantam suficiente transparência das informações relativas à propriedade".

${ }^{11}$ Esta última formulação ("todos os membros do público") foi introduzida pela Diretiva (UE) 2018/843, de 30 de maio de 2018, que alterou a Diretiva 2015/849 (na versão original estava "quaisquer pessoas ou organizações que possam provar um interesse legítimo").

12 Esta disjuntiva serve abarcar também as ações escriturais. 
como sociedade, revelando-se somente o sócio "ostensivo" e ficando na sombra o sócio "oculto".

A melhor explicação para aquela designação parece ser esta: a sociedade anónima, ao invés da sociedade em nome coletivo (tipo prevalecente no início do séc. XIX), não podia então conter na respetiva denominação o nome de nenhum sócio, dava-se a conhecer unicamente por designação do objeto social.

Depois, importa sublinhar que as sociedades anónimas (e suas antecessoras) sempre conviveram com as ações nominativas. Mais: nos séculos XVII e XVIII só muito excecionalmente se encontram ações ao portador.

E hoje, na União Europeia, já há países que aboliram as ações ao portador. Portugal é um deles: fê-lo pela Lei 15/2017, de 3 de maio.

\section{REFERÊNCIAS}

ABREU, J. M. COUTINHO DE., Governação das sociedades comerciais, 2aㅡ. ed., Almedina, Coimbra, 2010, p. 91.

, Remunerações dos administradores e transações com partes relacionadas na Diretiva dos Direitos dos Acionistas II, In: Direito das sociedades em revista, v. 19, Coimbra, 2018, p. 18-26.

ANTUNES, José Engrácia (2018), "A titularidade por conta de participações sociais - breve apontamento". Direito das Sociedades em Revista, a. 10, v. 19. Lisboa: Almedina, pp. 51-70.

COURET, ALAIN., ADR, EDR, nominees, trustees, partnerships, global custodians, etc.", Rev. Sociétés, 1999, p. 554

FIGUEIREDO, ANDRÉ. Titularidade indireta de ações e exercício de direitos de voto, In: Revista de Direito das Sociedades, n. 3, a. 4, 2012, p. 512.

GOWER \& DAVIES. Principles of modern company law, Sweet \& Maxwell, London, 2012, p. 455. HAMILTON, Robert W., The law of corporations, West Group, St. Paul-Minnesota, 2000, p. 258-259.

MARTINS, AleXandre Soveral., Cláusulas do contrato de sociedade que limitam a transmissibilidade das acções, Almedina, Coimbra, n. 75, 2006, p. 224.

MERKT, Hanno. "Die Geschichte der Namensaktie" em R. VON ROSEN / W. G.SEIFERT (Hrsg.), Die Namensaktie, Deutsches Aktieninstitut, 2000, p. 90-92.

MOHAMED, JEAN., Aktien und Aktienrepräsentanz im Zuge des Transparenzregisters (?),Vol. 38, n. 45, 2017, págs. 2133-2142. 